Original Research Article

\title{
Discussion on the Selection and Maintenance of Indoor
}

\section{Flowers}

\author{
Yijing Wang,Junfeng Shi, Wenyue Liu \\ Horticultural garden college, Cangzhou Agroforestry University, Hebei, China
}

\begin{abstract}
With the development of material life, the importance of plants in life has become increasingly prominent, and indoor flowers are also popular. As we all know, plants have purified air, refreshing brainwashing, promote sleep, sterilization and other effects, such as mint, Clivia, aloe and so on. Therefore, the choice of plants corresponding to their own needs is particularly important, while to note that some flowers should not be placed indoors. And different flowers on the water, temperature, light, soil and other requirements are not the same.
\end{abstract}

KEYWORDS: selection, planting, conservation

\section{Preface}

At present, China's large and medium-sized cities are growing rapidly, economic and cultural, with people's living standards and cultural literacy level of continuous improvement, flower culture and social material civilization and spiritual civilization have a close relationship. In the large and medium-sized cities of the office buildings, industrial and mining enterprises, schools, venues and indoor and outdoor potted flowers constitute a variety of patterns to green, beautify the people's living and working environment, to create a pleasant life, rest and serene atmosphere.

\section{Discussion of indoor flowers}

The family of flowers is not a few, but it does not make much use. In accordance with the room function flowers, has become a new fashion.

Beijing Forestry University Ph.D., Beijing Agricultural Technology Promotion Station expert Li YunFei said, colorful flowers cluster tight way of flowers, and now has long been outdated. Now many families popular 'functional plants', not only for viewing, but also conducive to health.

Often encounter the situation of smoking guests, the owner of the second-hand smoke is angry due to face, or the family was very big addiction, bad quit. Then you can plant Swedish ivy in the living room, leaves on the tiny pores can effectively absorb the air in the formaldehyde and nicotine, into harmless sugar and amino acids, but also absorb the smoke generated by smoking, resist nicotine in the carcinogenic substances; Grass can be used to convert nicotine from air to oxygen and carbon dioxide. These two plants are very suitable for keeping in the living room.

Chlorophytum, green radish, iron fern, those grass and flowers can purify the air, absorb harmful gases, and some can also make people relax to help sleep. Violet, rose and other flowers also help the role of sleep, these flowers can try to keep in the bedroom.

And lavender, mint and jasmine, these flowers have a very good refreshing effect, can help the brain excited, the most suitable place is place on the study room table, it can improve the efficiency of learning and work.

There are also many newly renovated houses that also require the care of these functional flowers, such as Boston ferns that absorb about 20 micrograms of formaldehyde per hour and therefore considered the most effective biological 'purifier'.

Ivy, rose, rose, aloe and evergreen, can effectively remove the indoor trichlorethylene, hydrogen sulfide, benzene, phenol, hydrogen fluoride and ether. Some of the fir plants can also absorb some of the decoration pollution, and turtle

Copyright (C) 2017 -. This is an Open Access article distributed under the terms of the Creative Commons Attribution-NonCommercial 4.0 International License (http://creativecommons.org/licenses/by-nc/4.0/), permitting all non-commercial use, distribution, and reproduction in any medium, provided the original work is properly cited. 
bamboo, horseradish, etc., also has a good purification and sterilization function, suitable for placing in the new house and bathroom.

Li YunFei pointed out that love flower is a very healthy habit, but if you can understand these flowers and plants 'character' can be better condemnation, on their own health play a positive role in helping.

The choice of indoor flowers should be on the human health as the primary, the same can only release the air of flowers for the first choice, and then is beautiful, decorated room effect.

\section{The choice of indoor flowers}

\subsection{Selection of several conditions to note:}

\subsubsection{Planted flowers should be adapted to local soil and water and climate;}

\subsubsection{Cultivate easy to live, evergreen, easy to be flowering varieties;}

\subsubsection{Choose to adjust the indoor air at night varieties;}

\subsubsection{Choose a small area, but can receive a better landscaping effect of the species.}

\subsection{Suitable for indoor planting of woody flowers}

\subsection{1- Ivy}

Slightly shade, the indoor should be placed in a bright place to keep the soil moist is appropriate, as the main vine foliage plants. The environment is too dark and easy to get sick, point a lamp is enough for it to grow. Ivy is currently the most effective indoor plants to absorb formaldehyde, per square meter of ivy leaves can absorb formaldehyde 1.48 $\mathrm{mg}$, Ivy can also absorb benzene and other toxic and harmful substances and dust particles.

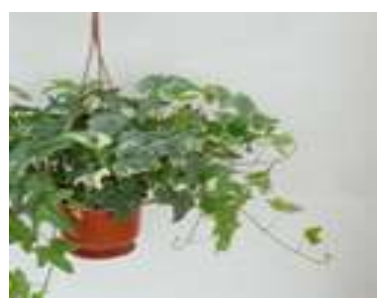

Ivy Pocket Coconut
Pocket coconut

\subsection{2 -Pocket coconut}

Strong resistance, potted soil and then watering. Although small, but still full of coconut form. Petite and exquisite body, suitable for viewing on the table, there are relatively large 7-inch potted plants can be arranged as an office screen.

\subsection{3 -Yellow coconut}

Alias: Squid, yellow butterfly coconut. Half-day watering, pelvic surface has been dry and then watering. Its degree of light to moderate, and prefer a slightly higher humidity environment, very suitable for indoor. In the removal of indoor toxic gas effect, the yellow coconut family of indoor plants first.

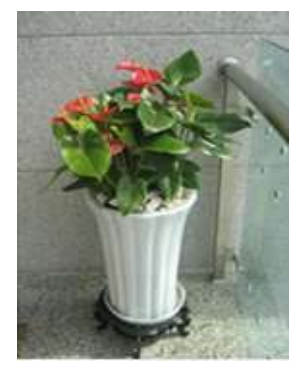

Trumpet sunflower palm Anthurium 


\subsection{4- Flamingo flowers}

Alias: Anthurium. Put light bright place, soil surface slightly dry watering. Traditionally used as a cut flower, there are many potted varieties listed. Leaves are smooth and bright, bright and bright flowers. Cultivation of light to be bright, otherwise it is not easy to be flowering.

\subsection{5 -Devil's ivy}

Alias: Green radish. The first 'plant', no one does not know. Easy cultivation, regardless of soil water plowing, potted pots, easy to use. If you think of a plant killer, choose it to ensure that you can regain confidence. Improve the quality of air to eliminate harmful substances. Green radish vitality is very strong, the ability to absorb harmful substances is also very strong, can help the person who do not often window ventilation room to improve air quality. Green radish can also eliminate formaldehyde and other harmful substances, its function as much as Ivory, Chlorophytum.

Green radish bamboo Bamboo

\subsection{6- Bamboo}

The elimination of bacteria and viruses, bamboo plant it has contains aromatic aroma components, can clear the air bacteria and viruses, with health care function, so the release of the smell of bamboo leaves have bactericidal antibacterial power. In addition, there is a high medicinal value of bamboo, digging its fleshy root, wash away the above dust dirt, dry or ready to use, leafy branches with the use of mining, are cough lungs, cooling blood the effect of detoxification.

\subsection{7- Adiantum capillus-veneris}

Each hour can absorb about 20 micrograms of formaldehyde, so it is considered the most effective biological purifier. All day with the paint, paint dealings, or people who like smoking around, you can then put a pot of workplace Adiantum capillus-veneris. In addition, it can inhibit the release of xylene and toluene in computer monitors and printers.

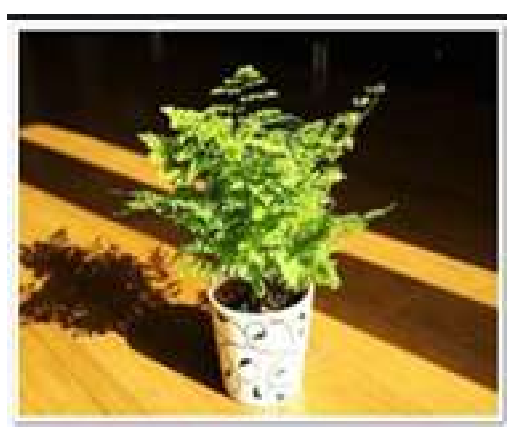

Adiantum capillus-veneris

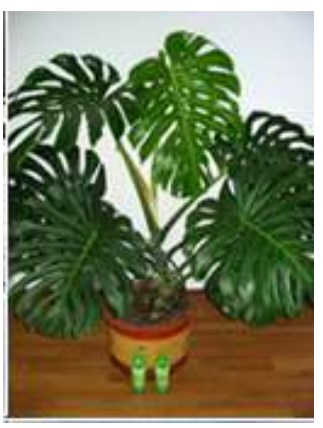

Swiss cheese plant

\subsection{8 - Swiss cheese plant}

It is clear the effect of formaldehyde in the air is obvious, to improve the indoor air quality, improve oxygen content is very helpful. Moreover, its elegant shape, the leaves are relatively smooth and beautiful, the fruit can be cooked after ripe.

\subsection{9 - Malabar chestnut}

Against the combustion of tobacco. Malabar chestnut four season evergreen, through the photosynthesis to absorb toxic gases to release oxygen, can more effectively absorb carbon dioxide and carbon dioxide pollution. 


\subsection{Suitable for indoor cultivation of herbal flowers}

\subsection{1 - Chlorophytum}

A pot of orchids in the 8 to 10 square meters of the room is equivalent to an air purifier, can effectively absorb the air of formaldehyde, carbon monoxide and other toxic chemicals. It can be in 24 hours, killing $80 \%$ of the harmful substances in the room, absorb $86 \%$ of formaldehyde; can fire, electrical appliances, plastic products emitted carbon monoxide, nitrogen dioxide exhausted.

\subsection{2 - Aloe Vera}

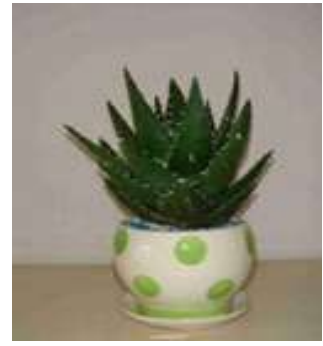

Chlorophyta

Aloe Vera

A bowl of Aloe Vera is equivalent to nine sets of biological air cleaners potted Aloe Vera air purification experts in the world. A bowl of Aloe Vera is equal to nine biological air cleaners, can absorb formaldehyde, carbon dioxide, sulfur dioxide, carbon monoxide and other harmful substances. Especially for formaldehyde absorption is particularly strong. In the 4 hours of light conditions, a pot of Aloe Vera can eliminate one square meter of air $90 \%$ formaldehyde, but also to kill harmful microorganisms in the air, and can absorb dust, the purification of the room environment has a significant effect. When the indoor air is too high the leaves of aloe will appear spot, this is the help signal. If the indoor increase in a few pots of Aloe Vera the indoor air quality will tend to normal.

\subsection{3 - Cactus, Echinopsis oxygona}

This kind of plant itself has many different characteristics, in the night can still absorb carbon dioxide, the release of oxygen, but also and Chlorophytum, Aloe Vera and other sunshine plants form complementary advantages, in the absorption of harmful gases at the same time has a strong absorption of radiation, but also has a strong anti-inflammatory sterilization effect. Can be placed in the TV, near the computer, and we also recommend cactus, Echinopsis oxygona and Chlorophytum and other plants to accompany the release, the formation of complementary, the effect is better.

Echinopsis oxygona

\subsection{4 - Lucky bamboo}

Lucky bamboo suitable for healthy plants in the bedroom, can help do not often open the window to improve the air quality of the room, with the disinfection function, especially the bedroom, can effectively absorb the exhaust gas to improve the privacy of the bedroom.

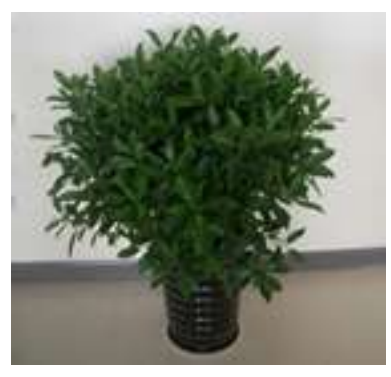

Stephanotis floribunda

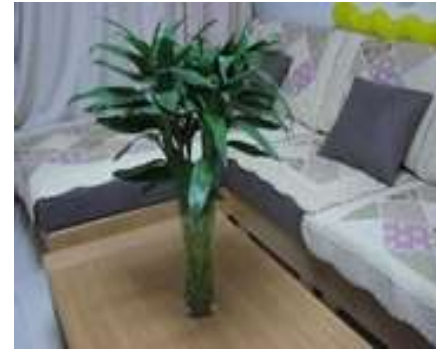

Lucky bamboo 


\subsection{5 - Stephanotis floribunda}

Produced by the volatile oil has a significant bactericidal effect can relax, is conducive to sleep and also improve to work efficiency.

\subsection{6 - Clivia}

Release oxygen, smoke freshener, an adult Clivia, a day and night can absorb 1 liter of air, the release of $80 \%$ of the oxygen, in extremely weak light can also occur under photosynthesis, it will not be distributed in the night of carbon dioxide, in the more than ten square meters of indoor two or three pots of gentlemen can smoke indoor smoke can be absorbed, especially in the cold winter in the north, due to doors and windows closed, the indoor air is not in circulation, Clivia will play a very good role in regulating air, keep the indoor air fresh.
Clivia
Mint

\subsection{7 - Mint}

Not only to resist ozone, as well as bactericidal effect.

\subsection{Plants that should not be planted indoors}

\subsection{1- Indoor should not be placed too much plants}

Plants in addition to photosynthesis, but also to breathe, that is inhalation of oxygen, the release of carbon dioxide. If there are too many indoor plants, it will increase the concentration of carbon dioxide in the air. Especially in then night, plant photosynthesis is mostly inhibited, and breathing is very strong, the formation of oxygen with the people of the situation, so that the indoor concentration of carbon dioxide higher, affecting people's health. In particular, some high oxygen consumption of flowers: such as clove, night incense, etc., when photosynthesis, a large number of consumption of oxygen, affecting human health. Night to stop photosynthesis at night, a large number of exhaust emissions, will make high blood pressure and heart disease patients feel depressed.

\subsection{2 - Produce smell of flowers}

Pine, cypress class, jade clove, elderberry and so on. Pine and cypress class secretion of lipid substances, release a thick osmole oil smell, smell a long time, will cause loss of appetite, nausea. The smell of clove fragrance will cause people to breathe and bored.

\subsection{3 - Make people allergic flowers}

(1) Lantana camara, Hydrangea, Geranium and so on. As long as people touch, touch this kind of flowers, it will cause skin allergies, while the itching unbearable, rash.

(2) Clove, Milan, Jasmine, etc., they have a strong flower fragrance, easily lead to respiratory allergies.

There are some plants with toxins, such as Oleander, Narcissus, Poinsettia, Thorny cactus, etc., they are caused by skin inflammation, severe can cause nausea, poisoning, chest tightness and other symptoms. Especially children with a family, children are not sensible, like playing with flowers and leaves, and even biting flowers to play, it will be very dangerous.

\subsection{5 - Patients indoors do not plant flowers}

The fungi spores produced in the soil of the flower pots spread into the indoor air, causing the human body surface or deep infection, and may invade human skin, respiratory tract, external auditory canal, meningeal and brain. This is 
the original suffering from illness, poor physical condition, such as worse, especially for leukemia patients and organ transplants greater harm.

Liaoning Provincial Landscape Architecture Association expert Professor Li ZuoWen answered these questions, he believes that the 'dripping Guanyin' worry is redundant, it is not in 52 kinds of cancer-promoting plants. It is toxic, but can be assured.

\subsection{6 -Toxic flowers}

(1) Cercis chinensis: It spread out the pollen, such as contact with people for too long, will induce asthma or increase the symptoms of cough;

(2) Shameplant: For a very ornamental value of small shrubs, containing poisonous shameplant, stems and leaves of the liquid juice can cause allergic reactions, so that the skin redness, itching, and even eyebrows sparse, hair yellow, serious hair loss;

(3) Rhododendron - Yellow rhododendron contains tetracyclic diterpenoid toxins, poisoning caused by vomiting, difficulty breathing, limb numbness;

(4) Arum-lily: Flowers are toxic, containing many herbal calcium crystals and alkaloids, eating can cause coma and other symptoms of poisoning;

(5) Lily: Flowers bright, elegant fragrance, bulbs edible, for the tonic to share. But the flowers contain a strange doping, although the content was low, but if the stagnant in the bedroom after a long sniff, also can produce 'drunk flower' symptoms, people too excited, look uneasy, and even night cannot sleep, cannot be taken lightly;

(6) Jimsonweed (Datura metel): Annual herbs, big flowers, strange, bright color, arouses love and affection. Plants, flowers toxic, fruit highly toxic, including atropine and scopolamine and other toxic drugs. Eating mosaic, began to make people laugh, and then nerve disorder, and finally lost consciousness, in fact, 'anesthesia' role;

\section{Flower management measures}

\subsection{Conservation of indoor flowers to control the four elements}

\subsection{1 - Moisture}

As the saying goes, 'Plant life does not live in water, so good is fat', it can be seen, the water conservation throughout the plant occupies the most eminent position.

(1) Plant watering time according to plant varieties, soil and air humidity and other comprehensive consideration. Before the watering, through the 'look, knock, twist' and other methods to identify the indoor potting water content, if the surface of the soil is lighter or gray for the lack of water, such as finger joints gently tap the pot In the upper part of the pelvic wall, issued a crisp sound is the lack of water, such as twisting with the fingers of the basin is powder is also the lack of water;

(2) In the watering to adhere to the 'do not pour, pouring is poured,' the basic principles, should not pour the lumbar water, that is, the upper half of the wet, the second half dry. For potted plants, when the basin is dry and the soil pores are too large, the water easily penetrates from the soil pores and the pelvic wall, and is not completely absorbed by the soil and the roots;

(3) Often in the plant leaves spray water, not only can increase the air humidity, you can also remove the dust, keep the foliage clean, increase gloss, promote photosynthesis.

\subsection{2 - Fertilizer}

(1) Fertilizer is the grain of plant growth. For indoor potted flowers, fertilizers to adhere to the 'Effect of thin application' principle, should not apply fertilizer, fertilizer and irritating smell of fertilizer;

(2) Fertilization can be based on plant varieties, growth period, growth potential and season and other elements combined with soil, watering. Such as rhododendron, gardenia and other bogey use of alkaline fertilizer, green giants, a leaf blue and other leaves to the main flowers can be applied to the emphasis on the application of nitrogen, Chrysanthemum, Dahlia, etc. in the flowering period to apply the right amount of fertilizer, Gorgeous flowers, Prynne, Osmanthus and other fragrant flowers into the flowering period, should be appropriate amount of phosphorus, potash, to facilitate the rich flowers and so on; 
(3) From the season, the spring and summer flowers grow fast, growing vigorously, the amount of fertilizer can be appropriate, into the autumn after the temperature gradually reduced, decreased flower growth should be less fertilization, winter flowers, winter should be in the dormant state should stop fertilization.

\subsection{3 - Temperature}

(1) The temperature is too high or too low, the normal physiological activities of plants are destroyed, the growth will stop, or even the whole plant death, so pay attention to the temperature changes, and timely take appropriate measures to adjust to ensure the normal growth of plants;

(2) The largest impact on the indoor flowers is the winter low temperature and 'late spring', should try to put the pots in the sunny, high temperature indoor windows, balconies, not on the ventilation aisle, for vulnerable to frozen plants plastic film can be used to cover the winter, winter and early spring should be at noon with warm water, to avoid excessive temperature caused by injury. When the indoor temperature is too high in summer, the flower pot can be placed in the door and aisle and other ventilation, but to avoid direct sunlight, or often to the foliage spray or water spray around the pot, you can also play the role of cooling.

\subsection{4 - Light}

(1) All things grow by the sun. Indoor flowers to accept the sun and light exposure, can fully meet the growth and development of plants, but some parts of the light is too weak, will make plant branches slender, internode is too long, leaves thin leaf color is not correct, but also easy to pests and diseases, and even some pattern or striped varieties will lose the unique ornamental value;

(2) Plants have photo taxis, all the potted plants every week to turn the flower pot, to avoid the directional light caused by plant partial crown, affecting the viewing effect. Usually placed in the indoor plants every ten days to move to the balcony or outdoor place, to accept some sunny or fresh air, which is very beneficial to the growth of the plant, but to avoid the summer sun light burns plant leaves.

\subsection{Management of indoor flower cultivation}

\subsection{1 - Watering times, time and watering of potted flowers}

(1) After the spring began to rise in temperature, flowers into the growth period, watering should be gradually increased. General flowers every 2 to 3 days pouring a water, then with the temperature rise, gradually increased to once a day water, to the July high temperature stage 2 times a day water. Watering time is between 10 am and 4 pm;

(2) Different types of flower habits are different, there is a large difference in water demand. Ferns, orchids, such as kiwi and other hi wet flowers should be more water; Sedum Branch, Cactus Branch, Agave Branch and other hi drought flowers less watering; bulb water cannot be too much water;

(3) Different growth and development stage of the different water requirements. From the dormant period into the growing period of the watering water to gradually increase; vigorous growth period of flowers, to more water; flower bud differentiation early, squatting stage, before the basin to be deducted; flowering early and strong period of watering, Full flowering period should be appropriate watering; new pots or new pots of flowers, the first water must be poured;

(4) The nature of different soil cultivation, water retention capacity is very different, watering should also be different. Sandy loose soil, water retention capacity is poor, should be more watering; sticky soil, water retention capacity, should be less watering;

(5) Watering also depends on the size and texture of the flower pot, pots small, pots of dry fast, the number of watering to increase, while the flower pot is the opposite. The basin water, the water permeability is good, the water loss through the wall of the wall is less than the moisture consumed by the flowers, and the water is more water. The pots, glaze basins and purple basins are fine, and the water permeability is poor. ; Plastic pots impermeable and airtight, should be less watering;

(6) Water quality to rain, pond water, river water is most appropriate. General flowers can also be used with tap water, but it is best to store the tap water for 1 to 2 days before use.

\subsubsection{Methods and dosage of fertilization}

(1) Potted in the spring generally used base fertilizer and topdressing of fertilizer application in two ways: in the flower planting or before is on applying fertilizer in the soil fertilizer. Basin or on the need for pots of flowers in the spring, combination or changing some basic fertilizer, and manure to organic fertilizers, and beans such as livestock 
manure, compost, bone meal, and so on, must be fully composted before being used. Fertilizer usage does not exceed $20 \%$ of the total amount of potting soil, mixed with soil cultivation into or put fertilizer into the pelvic floor or around the basin, should never be allowed plant roots directly falling on the pelvic floor base fertilizer, should be between roots and basal separated by a layer of Earth.

(2) During growing of flowers, add fertilizer whenever you want called fertilization. Liquid fertilizer dominated much dressing, which is beneficial to soil and roots. Top dressing with "thin-fat effect" principle, both to organic fertilizer applied to inorganic fertilizer. Start every 10-15 days 1, as temperatures rise and increase of plants, fertilizing should gradually increase in number, every 7-10 days 1, fertilizer solution concentration should be increased to $10 \% \sim 15 \%$. Per kg of cake adding 10 grams of ferrous sulfate, add water after full maturity, which is alum and fertilizer. Alum and fertilizer used in acid soil flowers, Tan lines can be dark green leaves. Inorganic fertilizers, urea, ammonium sulfate, calcium superphosphate, potassium sulfate, etc., must be aware of when using concentration should be controlled in the $0.1 \% \sim 0.5 \%$, too high concentration so as not to cause harm;

(3) The fertilizer solution sprayed on the plant leaves through stomata was absorbed by plant, this fertilization method is called foliage top-dressing. Root top dressing usually flower flourishes or lack of certain nutrients are used. 4-5 hours after the spray can be absorbed by plants in General, can be absorbed by plants within a 24-hour trip, the effect lasts 7-10 days. The fat evenly sprayed on both sides of the leaf, spray to wet. 4.3 potted plant requires high daytime temperatures to temperature and photosynthesis formation of carbohydrates; low night temperatures, can inhibit respiration, decomposition of carbohydrates, some plant must be carried out at temperatures higher than $25^{\circ} \mathrm{c}$ under conditions of flower bud differentiation and after a certain breaking dormancy and flowering low temperature, such as rhododendron, Camellia, plum blossom, gladiolus, tuberose, canna etc. Some plants need to flower bud differentiation in a low temperature or low temperature. Such as sowing grass Calendula flowers, daisies, etc.

\subsection{Pest control of indoor flowers}

Family planting and breeding of pests and diseases, if use chemical control, although the effect is good, but it will bring pollution problems, adverse health. Now introduced some in the family planting potted plants in the absence of injury, will not pollute the environment and safe and reliable and simple method, after the author long-term application proved the reliable results.

3.3.1 - Fresh pepper or dried chili 50 grams, add water 5000 grams, cook for half an hour, spray plant, can kill aphids, red spider. Pick up the day seven-star pepper 1, do not cook, mashed to the slag, add 5 times the water mixture, spray it, and it can prevent aphid, caterpillars.

3.3.2 - Chopped 50 grams of green onions. Add 1500 grams of water to soak it for 24 hours and filter, spray with juice, can control aphids, powdery mildew.

3.3.3 - Garlic to pieces, put it into the pots of soil, 2 to 3 days later, can destroy the pots of ants, earthworms. Or take the smashed garlic 30 grams, add water 10 liters of stirring, soaking, with its liquid watering basin soil, can control aphids, red spiders and scale insects and other insect pests.

\section{Conclusion}

Indoor pots of flowers have become an important part of the indoor configuration, the family room in addition to the layout of the beautiful furniture and some furnishings, such as potted flowers, flower arrangement for decoration, both to the room to bring the breath of life, and make people pleasing to the eye, cultivate sentiment. Indoor potted plants can be green, landscaping and fragrant indoor environment, can make indoor space full of vitality, people kind of close to the natural feeling. So, the cultivation and management of indoor potted plants is a very meaningful and important research project.

\section{References}

1. Garden trees. Qiu Guojin. China Forestry Press, 2005.

2. Garden plant cultivation. Zhou Xingyuan. Beijing Higher Education Publishing, 2006.

3. Introduction to Chinese flower. Chen Junyu, Cheng Xuke. Shanghai Culture Publishing House, 1990.

4. Indoor flower conservation essentials. Lu Sicong. China Forestry Press, 2002.

5. Department of Landscape Architecture, Beijing Forestry University, 2010.

6. Garden plant cultivation. Zhou Xingyuan. Beijing Higher Education Publishing, 2006.

7. Indoor environment and indoor plant conservation management. Xiong Heping. Flowers bonsai .1999. 